\title{
Eficiência de utilização de adubação orgânica em forrageiras tropicais
}

\author{
Camila da Silva Castro ${ }^{1}$, Ulisses Gabriel Moraes Lobo ${ }^{1}$, Lucas Matheus Rodrigues ${ }^{1}$, Clarice \\ Backes $^{1}$, Alessandro José Marques Santos ${ }^{1}$
}

${ }^{1}$ Universidade Estadual de Goiás, Câmpus São Luís de Montes Belos, São Luís de Montes Belos, Goiás. E-mail: camilacometa@hotmail.com, ulissesgabriellobo@hotmail.com, lucasmrzoo@gmail.com, clarices.backes@ueg.br, alessandro.santos@ueg.br.

Recebido: 29/05/2016; Aceito: 24/10/2016.

\section{RESUMO}

A adubação orgânica pode influenciar de forma positiva e significativa o desenvolvimento de gramíneas forrageiras. Dois experimentos foram instalados em vasos, em casa de vegetação, com o objetivo de avaliar o efeito de doses de esterco bovino no desenvolvimento dos capins Brachiaria brizantha (Syn. Uroclhoa brizantha) cv. Marandu e Panicun maximum cv. Mombaça. O delineamento utilizado para cada experimento foi em blocos ao acaso com quatro repetições. Para o capim-marandu foram utilizados cinco tratamentos constituídos por quatro doses de esterco de bovino curtido: 0; 9; 18 e $27 \mathrm{Mg} \mathrm{ha}^{-1}$ (base seca) e mais um tratamento com adubação inorgânica (AI), na dose recomendada. $\mathrm{O}$ experimento com o capim-mombaça consistiu de seis tratamentos: 0 , 4,5; $9 ; 18 ; 36 \mathrm{Mg} \mathrm{ha}^{-1}$ de esterco bovino e um tratamento com adubação inorgânica (AI). O aumento de doses de esterco proporcionou melhorias nas características produtivas das duas forrageiras estudadas. A máxima produtividade do capim-marandu foi obtida com a dose média de $24,3 \mathrm{Mg} \mathrm{ha}^{-1}$. Já o capim-mombaça respondeu até a dose máxima aplicada $\left(36 \mathrm{Mg} \mathrm{ha}^{-1}\right)$. A AI proporcionou resultados semelhantes às duas maiores doses de esterco aplicadas. O esterco bovino pode ser utilizado na adubação de forrageiras substituindo em partes a adubação inorgânica.

Palavras-chave: Uroclhoa brizantha, Panicum maximum, fertilização, esterco bovino.

\section{Efficiency of organic fertilizer use for tropical forages.}

\begin{abstract}
The organic fertilizer can influence positively and significantly the development of forage grasses. Two experiments were conducted in pots in the greenhouse, in order to evaluate the effect of cattle manure rates on the development of Brachiaria brizantha (Syn. Uroclhoa brizantha) cv. Marandu and Panicun maximum cv. Mombasa grasses. The design for each experiment was a randomized block with four replications. For Marandu grass were used five treatments consisted for four rates of cattle manure: $0,9,18$ and $27 \mathrm{Mg} \mathrm{ha}^{-1}$ (dry basis) and a treatment with inorganic fertilizer. The experiment with Mombasa grass consisted of six treatments: $0,4,5,9,18$ and $36 \mathrm{Mg} \mathrm{ha}^{-1}$ of cattle manure and a treatment with inorganic fertilizer. The increase of cattle manure rates provided improvements in the productive characteristics of the two forages studied. The maximum productivity of Marandu grass was obtained with the rate of $24.3 \mathrm{Mg} \mathrm{ha}^{-1}$. The Mombasa grass responded to the maximum dose applied (36 Mg ha ${ }^{-1}$ ). The $\mathrm{Al}$ provided similar results to the two higher rates of cattle manure applied. The cattle manure may be used in the fertilization of fodder replacing in parts the inorganic fertilizer.
\end{abstract}

Key words: Uroclhoa brizantha, Panicum maximum, fertilizer, cattle manure. 


\section{Introdução}

A atividade agropecuária do Brasil é expressiva a nível nacional e internacional. O Brasil responde pelo maior rebanho bovino comercial do mundo; é o segundo maior produtor de carne bovina e o quinto maior produtor de leite (SEAB, 2014). É comum a prática da atividade em sistema extensivo de produção tendo a forragem como base da dieta (HOFFMANN et al., 2014), desta forma, a intensificação da produção e da forrageira utilizada é imprescindível.

O gênero Urochloa apresenta grande adaptação à região brasileira, caracterizada por solos ácidos e de baixa fertilidade. É também persistente, resiste à intensa e frequente desfolhação e apresenta elevado vigor de rebrota (ALVIM et al., 2002). O Panicum maximum cv. Mombaça caracteriza-se por alta produção de massa por área, grande porcentagem de folhas, valor nutricional alto, além de se adaptar bem às condições edafoclimáticas brasileiras (MÜLLER et al., 2002). É compreendido, dentre as espécies tropicais disseminadas por sementes, a mais produtiva, porém exigente em fertilidade do solo.

A correta adubação e correção do solo, bem como o manejo adequado da pastagem, são imprescindíveis, pois objetivam intensificar a produtividade da forragem e sua qualidade nutricional. Destaca-se a adubação nitrogenada que promove substancialmente o crescimento da parte aérea da planta. Em relação ao capim $U$. brizantha, cv. Marandu, a adubação nitrogenada é importante desde seu estabelecimento visando um bom manejo da pastagem, contribuindo significativamente para o número de perfilhos, folhas e comprimento das mesmas (ALEXANDRINO et al., 2010).

Mello et al. (2009), avaliando a produção do cv. Mombaça submetido à adubação nitrogenada durante dois anos no município de Goiânia - GO, em um Latossolo Vermelho Distrófico, observaram que a adubação com nitrogênio promoveu ao cv. Mombaça maior produção no período seco e chuvoso do ano. A quantidade de $\mathrm{N}$ necessária para a obtenção da máxima produtividade das forrageiras é elevada. O capim Mombaça responde a doses de até 500 e $510 \mathrm{~kg} \mathrm{ha}^{-1}$ de $\mathrm{N}$ (MELLO et al., 2009; MAZZA et al., 2009) e o capim Marandu a doses de até $300 \mathrm{~kg} \mathrm{ha}^{-1}$ de N (SILVA et al., 2003), representando custo elevado na produção.

A utilização de resíduos orgânicos pode ser uma forma de reduzir os custos com adubação, além de criar um descarte apropriado para os mesmos. De acordo com Silva et al. (2012), a adubação proveniente de dejetos de animais pode ser uma ótima alternativa para pastagens, oferecendo boas concentrações de nutrientes, principalmente do N. É uma alternativa de custo bem inferior a adubos formulados, tornando-se uma ótima opção para as empresas produtoras de carne, às quais necessitam descartar os resíduos produzidos pelos animais.

Dessa forma, objetivou-se com este trabalho avaliar o efeito de doses de esterco bovino no desenvolvimento dos capins Brachiaria brizantha (Syn. Uroclhoa brizantha) cv. Marandu e Panicun maximum cv. Mombaça

\section{Material e Métodos}

O estudo constituiu-se de dois experimentos em casa de vegetação, no município de São Luís de Montes Belos, GO. Utilizou-se vasos de polipropileno com capacidade para seis litros, preenchidos com solo classificado como Latossolo Vermelho Distrófico, textura argilosa, fase Cerrado, de acordo com a Embrapa (2013).

O solo foi coletado na camada de 0,0-0,20 m na Fazenda Escola da Universidade Estadual de Goiás, Câmpus São Luís de Montes Belos, GO, apresentando as seguintes características químicas: $\mathrm{pH}=5,8$; M.O. $=$ $42 \mathrm{mg} \mathrm{dm}^{-3} ; \mathrm{P}=5 \mathrm{mg} \mathrm{dm}^{-3} ; 22 ; 1,1 ; 45 ; 7$ e $75 \mathrm{mmol}_{\mathrm{c}}$ $\mathrm{dm}^{-3}$ de $\mathrm{H}+\mathrm{Al}, \mathrm{K}, \mathrm{Ca}, \mathrm{Mg}$ e CTC, respectivamente, e $\mathrm{V} \%=71$.

O delineamento experimental utilizado para cada experimento foi o de blocos ao acaso com quatro repetições, compreendendo quatro doses de esterco bovino curtido: $0,9,18$ e $27 \mathrm{Mg} \mathrm{ha}^{-1}$ (base seca) correspondendo a $0,100,200$ e $300 \mathrm{~kg} \mathrm{ha}^{-1}$ de $\mathrm{N}$ e mais um tratamento com adubação inorgânica para o capimmarandu e cinco doses de esterco bovino: 0, 4,5, 9, 18, $36 \mathrm{Mg} \mathrm{ha}^{-1}$ correspondendo a 0, 50, 100, 200, $400 \mathrm{~kg} \mathrm{ha}^{-}$ ${ }^{1}$ de $\mathrm{N}$ e mais um tratamento com adubação inorgânica para o capim-mombaça. Os resultados do esterco, expressos em base seca, foram: $\mathrm{pH} \mathrm{CaCl}_{2}, 6,9,11,0$; 4,$0 ; 5,2 ; 3,1 ; 1,0 ; 2,6$ e $240 \mathrm{~g} \mathrm{~kg}^{-1}$ de N, P, K, Ca, Mg, S e C orgânico respectivamente; e Relação C/N de 22.

A adubação inorgânica do capim-marandu consistiu de $80 \mathrm{~kg} \mathrm{ha}^{-1}$ de $\mathrm{P}_{2} \mathrm{O}_{5}, 30 \mathrm{~kg} \mathrm{ha}^{-1}$ de $\mathrm{K}_{2} \mathrm{O}$ e $200 \mathrm{~kg} \mathrm{ha}^{-1}$ de N. Para o capim-mombaça foi aplicado $100 \mathrm{~kg} \mathrm{ha}^{-1} \mathrm{de}$ $\mathrm{P}_{2} \mathrm{O}_{5}, 40 \mathrm{~kg} \mathrm{ha}^{-1}$ de $\mathrm{K}_{2} \mathrm{O}$ e $200 \mathrm{~kg} \mathrm{ha}^{-1}$ de N. As fontes utilizadas para ambos os experimentos foram o superfosfato simples $(\mathrm{P})$, cloreto de potássio $(\mathrm{K})$ e ureia (N).

O solo coletado foi peneirado, misturado com as diferentes doses do esterco bovino e colocados nos vasos. Nos dois experimentos a semeadura foi realizada em maio de 2013 utilizando-se 30 sementes por vaso. O desbaste aconteceu 15 dias após a emergência das plantas, deixando cinco plantas/vaso. O corte de uniformização foi realizado 30 dias após a semeadura. O $1^{\circ}$ corte foi realizado 60 dias após a semeadura, o $2^{\circ}$, 28 dias após o primeiro; e o $3^{\circ}, 30$ dias após o segundo corte, de modo que o intervalo entre os cortes foi denominado $1^{\circ}, 2^{\circ}$ e $3^{\circ}$ crescimentos. Para o tratamento 
que recebeu a adubação inorgânica, o nitrogênio foi parcelado em três vezes, sendo a primeira dose aplicada após trinta dias da emergência e as duas restantes após os cortes realizados. O fósforo e o potássio foram aplicados no momento da semeadura.

Antes de cada corte da planta foi determinado o número de perfilhos, pela contagem, a altura das plantas com o auxílio de uma régua graduada em três pontos do vaso e a Intensidade de Coloração Verde (ICV) das folhas com o clorofilômetro; as leituras com o clorofilômetro foram feitas em 10 folhas (primeira e segunda folha recém expandidas). Estas determinações foram realizadas antes de cada corte da forrageira em três períodos denominados $1^{\circ}, 2^{\circ}$ e $3^{\circ}$ crescimento.

Os cortes foram efetuados à altura de $10 \mathrm{~cm}$ do colo das plantas, coletando-se a parte aérea e dividindo-a em folhas e colmos mais bainhas. Esse material foi seco em estufa de circulação forçada a $65^{\circ} \mathrm{C}$, por 72 horas, para obtenção da matéria seca (MS). Com os dados de MS das frações folha/colmo, calcularam-se: a relação folha/colmo e a MS da parte aérea, representada em g/vaso. Os resultados obtidos foram submetidos à análise estatística utilizando o programa Sisvar (FERREIRA, 2015). A regressão foi utilizada para as doses e o teste de médias para comparar o tratamento de adubação inorgânica com as doses de esterco.

\section{Resultados e Discussão}

Verifica-se na Figura 1 que, para o capim-marandu, houve ajuste linear crescente da altura de plantas em função da aplicação de doses de esterco bovino, nos três crescimentos avaliados. A dose de $27 \mathrm{Mg} \mathrm{ha}^{-1}$ de esterco proporcionou alturas de 42,50 e $60 \mathrm{~cm}$ no primeiro, segundo e terceiro crescimento, respectivamente. Para o capim-mombaça houve ajuste quadrático no primeiro e terceiro crescimento. De acordo com as equações as doses estimadas de 26,5 e $30,7 \mathrm{Mg} \mathrm{ha}^{-1}$ de esterco proporcionaram as máximas alturas $(46$ e $78 \mathrm{~cm}$ respectivamente). No $2^{\circ}$ crescimento o efeito foi linear crescente.

Houve influência das doses de esterco bovino para o número de perfilhos/vaso nos dois capins estudados (Figura 2). Para o Marandu o efeito foi linear crescente no $1^{\circ}$ crescimento e quadrático no $2^{\circ}$ e $3^{\circ}$ crescimento. No $2^{\circ}$ crescimento, mesmo com efeito quadrático, a dose estimada está acima da dose aplicada. No $3^{\circ}$ crescimento a dose estimada de $24,4 \mathrm{Mg} \mathrm{ha}^{-1}$ de esterco foi a responsável pelo máximo perfilhamento do capimMarandu. Para o Mombaça o efeito foi quadrático nas três épocas avaliadas. De acordo com as equações ajustadas, às doses estimadas de 24,3; 31,7 e 31,8 Mg $\mathrm{ha}^{-1}$ de esterco proporcionaram os maiores números de perfilhos.

Para as duas forrageiras estudadas a AI proporcionou resultados semelhantes às duas maiores doses de esterco aplicadas. Araújo et al. (2009) estudando o efeito de duas doses de dois compostos orgânicos semicurados (20 e $40 \mathrm{Mg} \mathrm{ha}^{-1}$ de composto de esterco de bovino, e 10 e $20 \mathrm{Mg} \mathrm{ha}^{-1}$ de composto de esterco de galinha) e de adubação mineral nitrogenada no desenvolvimento de Brachiaria decumbens (Syn. Uroclhoa decumbens), verificaram que a adubação mineral proporcionou maior altura de plantas quando comparado aos demais tratamentos e atribuíram este resultado ao fato da maior resposta da forrageira ao $\mathrm{N}$ prontamente disponível. Porém, para a produtividade de massa seca da parte aérea os autores não verificaram diferença entre as fontes estudadas.
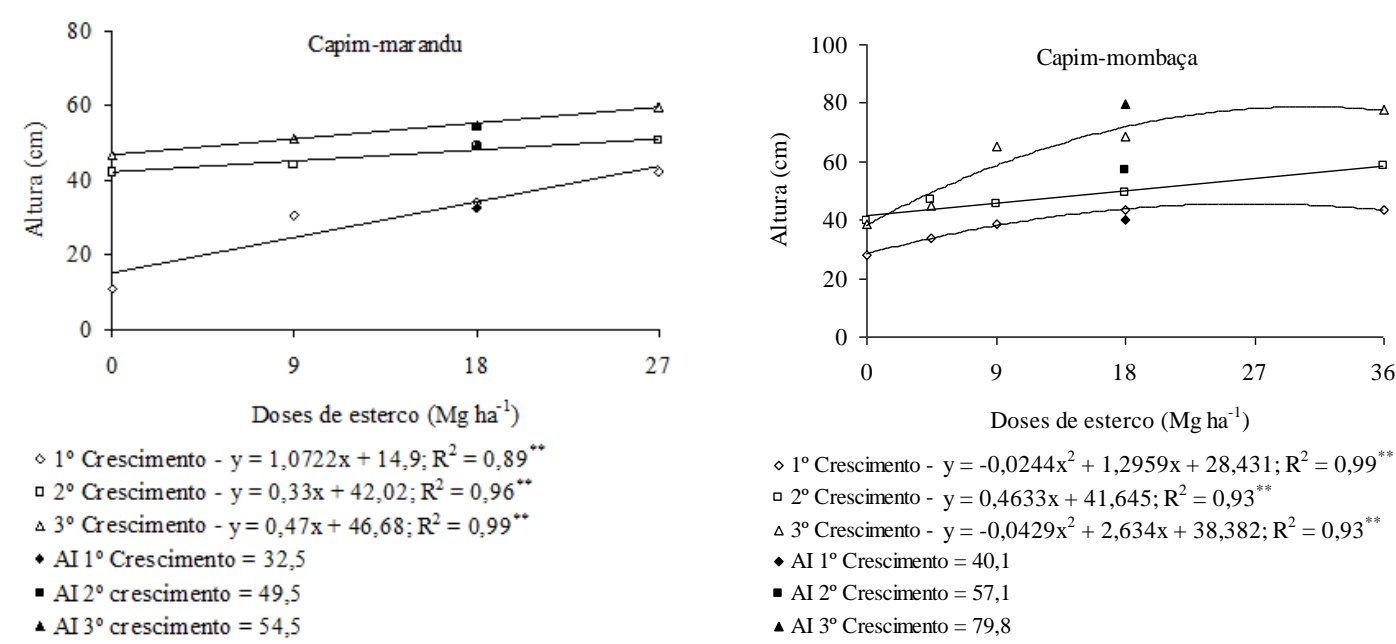

Figura 1. Altura de plantas do capim-marandu e capim-mombaça em função da aplicação de doses de esterco bovino e da adubação inorgânica (AI). São Luís de Montes Belos/GO. 

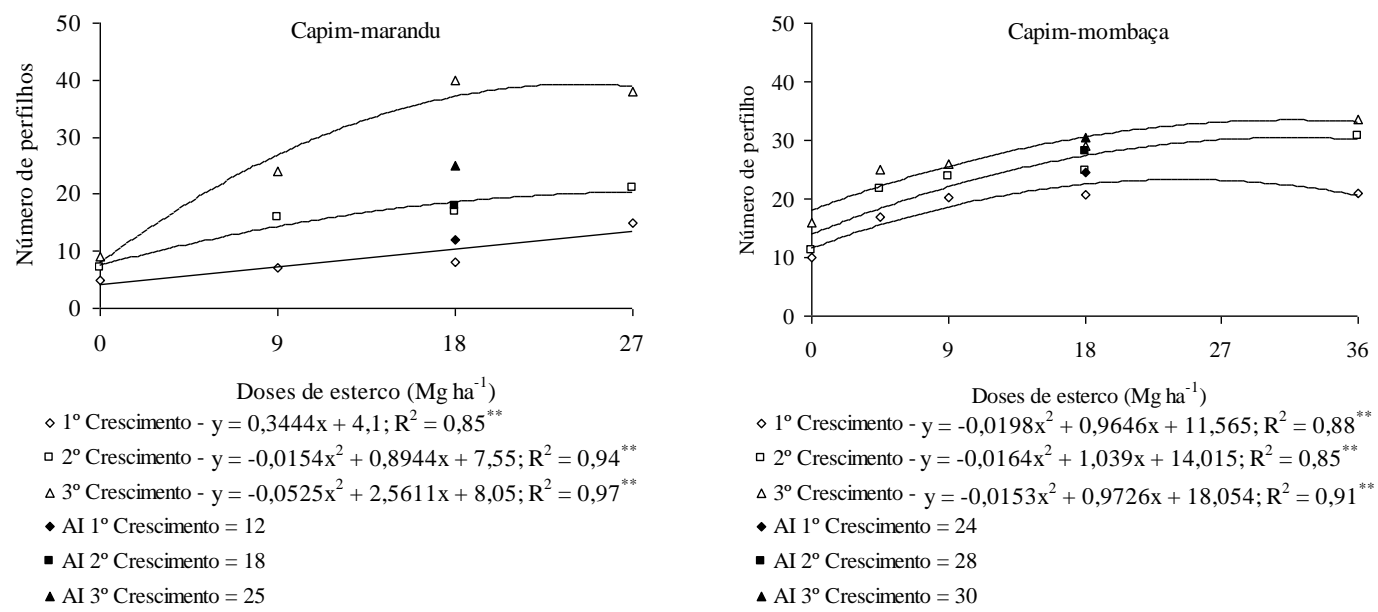

Figura 2. Número de perfilhos do capim-marandu e capim-mombaça em função da aplicação de doses de esterco bovino e da adubação inorgânica (AI). São Luís de Montes Belos/GO.

Araújo et al. (2011) ao avaliarem a resposta do capim-marandu submetido à adubação orgânica através do esterco bovino como fonte de $\mathrm{N}$, em substituição à adubação química (ureia) em diferentes proporções, em um Neossolo Quartzarênico órtico típico, constataram que o tratamento com o esterco bovino como fonte exclusiva de $\mathrm{N}$ proporcionou as menores alturas de plantas; a substituição de $11,36 \%$ da adubação química pela orgânica proporcionou a maior altura de $45 \mathrm{~cm}$.

Edvan et al. (2010), estudando a utilização de adubação orgânica em pastagem de capim-buffel, verificaram aumento do número de perfilhos com a maior dose do resíduo aplicada $\left(10 \mathrm{Mg} \mathrm{ha}^{-1}\right.$ de digesta bovina). Os autores atribuíram esse aumento à elevada concentração de fósforo (P) presente no resíduo (20 g $\mathrm{kg}^{-1}$ de massa seca). Neste experimento a quantidade de $\mathrm{P}$ presente no esterco foi de $4 \mathrm{~g} \mathrm{~kg}$ de massa seca e de acordo com as doses estimadas, as quantidades de $\mathrm{P}$ adicionadas estão entre 97 e $127 \mathrm{~kg} \mathrm{ha}^{-1}$.

A adubação inorgânica proporcionou resultados semelhantes às duas maiores doses de esterco utilizadas. $\mathrm{O}$ efeito do $\mathrm{N}$ no perfilhamento de forrageiras foi testado por vários autores. Alexandrino et al. (2005) testando doses crescentes de $\mathrm{N}(0,45,90,180$ e $360 \mathrm{mg}$ $\mathrm{dm}^{3}$ ) e frequências de corte (24 e 28 dias) no capimmarandu, independente da frequência, obtiveram resposta positiva para adubação nitrogenada com ênfase para a maior dose na densidade de perfilhos. De acordo com os autores o $\mathrm{N}$ contribui para o desenvolvimento tecidual da planta, portanto a falta desse nutriente no solo dificulta seu perfilhamento. Silva et al. (2005), em condições de campo, obtiveram maior intensidade de perfilhos do capim-marandu com a dose de $376 \mathrm{~kg} \mathrm{ha}^{-1}$ de N.

Neres et al. (2008), submetendo diferentes cultivares de Panicum maximum (Mombaça, Tanzânia e IPR - 86 milênio) a doses de nitrogênio $(0,100,200,300$ e 400 $\mathrm{kg} \mathrm{ha}^{-1}$ ), observaram resposta linear dos cultivares para o desenvolvimento de perfilhos em função da dose de $\mathrm{N}$ e maior altura $(82 \mathrm{~cm})$ das plantas com a dose de 290,16 $\mathrm{kg} \mathrm{ha}^{-1}$. De acordo com Caminha et al. (2010), a adubação nitrogenada promove maior renovação de perfilhos no pasto, consequentemente maior cobertura e proteção do solo e maior volume de massa.

O ICV das folhas do capim-marandu foi influenciado pelas doses de esterco apenas no $2^{\circ}$ e $3^{\circ}$ crescimento com efeito linear. A maior dose aplicada proporcionou os maiores índices 38,9 e 38,1. Para o capim-mombaça o efeito foi quadrático no primeiro crescimento e linear nos demais, com índices de cor 33,4; 37,0 e 40,4 (Figura 3). Os maiores índices obtidos demonstram que há uma maior concentração de nitrogênio na folha, resultando em maior capacidade fotossintética e maior potencial de acúmulo de açúcar e nutrientes no tecido vegetal, além de possibilitar maior aporte de biomassa. Tais fatores favorecem a disponibilidade e a qualidade da pastagem (MAZZA et al., 2009).

Para o capim-marandu verifica-se que o ICV foi semelhante quando comparado às avaliações $(38,9 \mathrm{e}$ 38,1 para a $2^{\circ}$ e $3^{\circ}$ avaliação respectivamente). Já para o capim-mombaça os maiores índices de cor foram observados na terceira avaliação. Estes aumentos dos índices de cor indicam que ocorreu predomínio da mineralização até os 120 dias da aplicação (data do último corte da forrageira). A adubação inorgânica proporcionou resultados semelhantes às duas maiores doses de esterco utilizadas.

No primeiro corte pôde-se constatar, por meio da equação de regressão, aumento linear na produtividade de massa seca do capim-marandu em função das doses de esterco. No segundo corte os dados referentes à produtividade de massa seca em função das doses de esterco se ajustaram a uma regressão quadrática, com o ponto de máxima estimado em $25,5 \mathrm{Mg} \mathrm{ha}^{-1}$ de esterco (14 g/vaso de massa seca). O mesmo ocorreu para o 
terceiro corte, porém, o ponto de máxima foi obtido com a dose de 20,5 $\mathrm{Mg} \mathrm{ha}^{-1}$ de esterco (16 g/vaso de massa seca) (Figura 4). Estas doses estimadas de esterco equivalem a quantidades de 283 e $228 \mathrm{~kg} \mathrm{ha}^{-1}$ de $\mathrm{N}$ respectivamente. Souza et al. (2010), ao estudarem a aplicação de esterco de curral antes do plantio do capim Marandu, após a colheita de uma leguminosa, comprovaram que a adubação orgânica influenciou de forma positiva e significativa o desenvolvimento da gramínea. Na maioria dos casos as equações lineares foram as que mais se ajustaram aos dados, indicando que as doses de esterco foram insuficientes para a produção máxima.

Ao se comparar as doses de esterco com a adubação inorgânica verificou-se que para o Marandu a AI proporcionou resultados semelhantes às doses de $18 \mathrm{e}$ $27 \mathrm{Mg} \mathrm{ha}^{-1}$ de esterco nos três cortes realizados. Já para o Mombaça, no primeiro corte, a AI proporcionou resultados melhores quando comparados aos demais, refletindo o estímulo imediato da cultura para emissão de novas folhas, em curto prazo, como resposta ao fornecimento de $\mathrm{N}$. Nos demais cortes a AI foi equivalente à dose mais alta do esterco utilizado demonstrando uma baixa taxa de liberação do $\mathrm{N}$ do resíduo utilizado. Araújo et al. (2009) também verificaram menor liberação de nutrientes do composto de esterco bovino, já que a adubação mineral (150 kg $\mathrm{ha}^{-1}$ de $\mathrm{N}$ ) proporcionou a mesma massa seca das plantas que receberam o dobro de $\mathrm{N}$ tendo o composto como fonte. A justificativa para as doses elevadas de esterco é a baixa concentração de nutrientes e a dependência da mineralização do resíduo para o efetivo aproveitamento dos nutrientes pelas plantas.
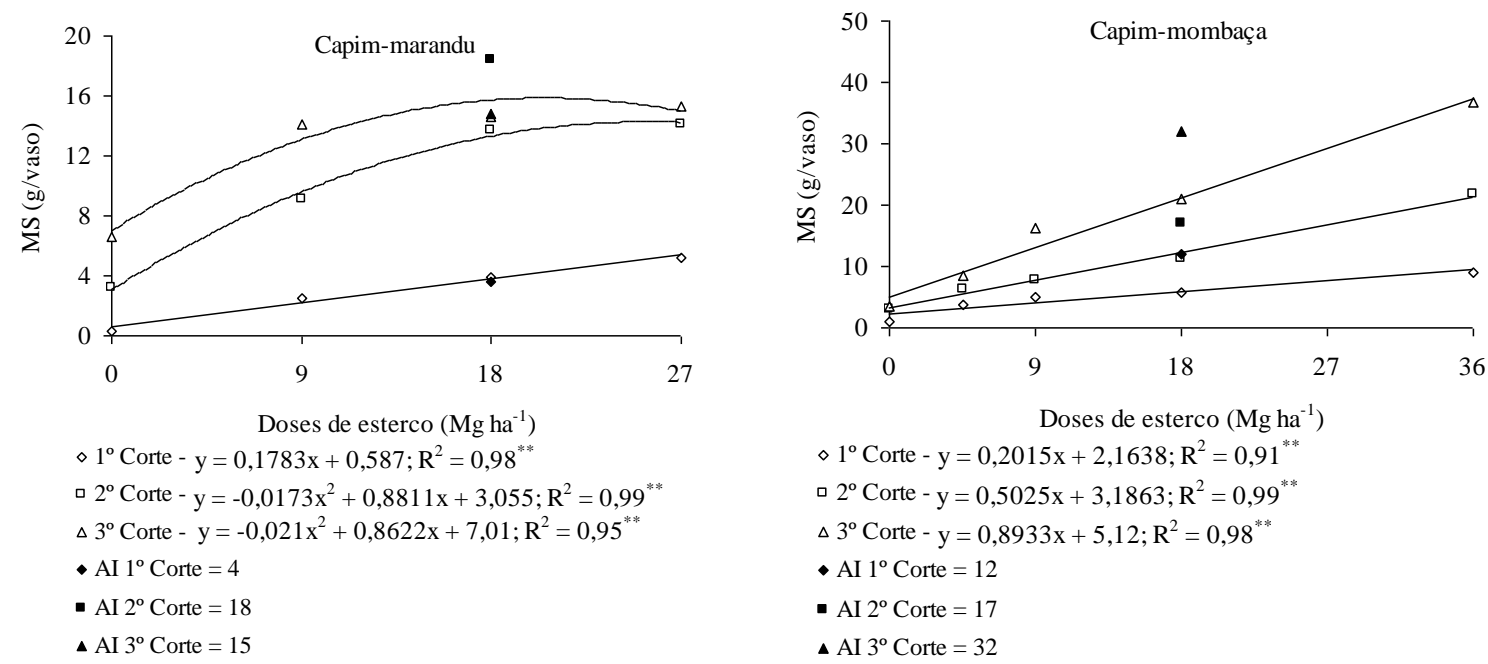

Figura 3. Intensidade de Coloração Verde (ICV) das folhas do capim-marandu e capim-mombaça em função da aplicação de doses de esterco bovino e da adubação inorgânica (AI). São Luís de Montes Belos/GO.
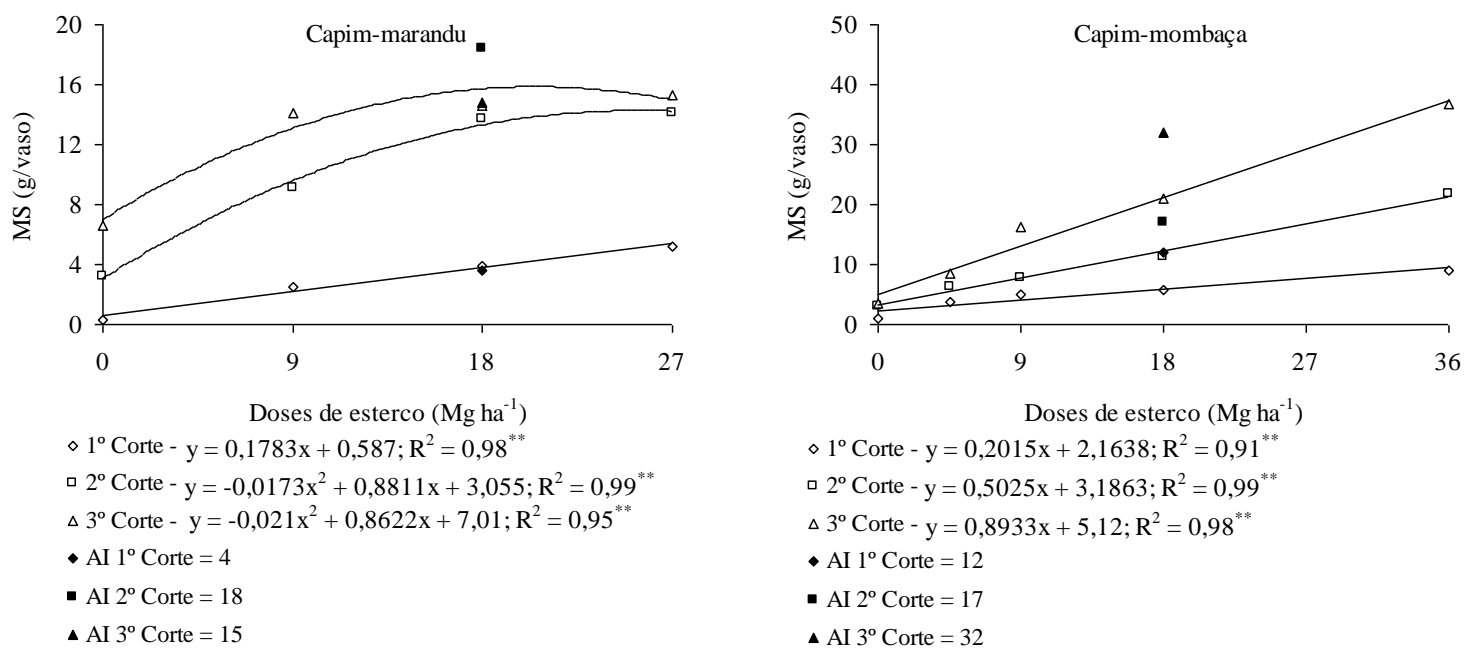

Figura 4. Matéria seca (MS) da parte aérea do capim-marandu e capim-mombaça em função da aplicação de doses de esterco bovino e da adubação inorgânica (AI). São Luís de Montes Belos/GO. 
Para o capim-mombaça houve efeito linear crescente nos três cortes realizados. A maior dose de esterco proporcionou as maiores produtividades de massa seca, 21,31 e $33 \mathrm{~g} /$ vaso para o $1^{\circ}, 2^{\circ}$ e $3^{\circ}$ corte (Figura 4). A quantidade de $\mathrm{N}$ disponibilizada pelo esterco bovino, mesmo na maior dose aplicada, não foi suficiente para a expressão do máximo potencial produtivo do capim. Mazza et al. (2009) também verificaram maior produção de massa seca do capim-mombaça com a maior dose aplicada (510 kg ha-1 $\mathrm{de} \mathrm{N})$.

Martins et al. (2006), estudando os capins Marandu e Mombaça em áreas degradadas, em resposta a aplicação de nutrientes (N, P e K) em solo calcariado e não calcariado, observaram que a adubação exclusiva com $\mathrm{N}$ conferiu maior produção de matéria seca ao capim Mombaça em comparação ao Marandu e que o N é o maior responsável pelo incremento da produção de matéria seca.

Para o capim-mombaça não houve influência das doses de esterco e da adubação inorgânica na relação folha/colmo. As doses de esterco influenciaram a relação folha/colmo do capim-marandu apenas no $1^{\circ} \mathrm{e}$ $2^{\circ}$ corte, sendo a resposta de comportamento quadrático (Figura 5). A derivada da equação indicou que a máxima relação no $1^{\circ}$ corte foi encontrada com a dose 23,5 $\mathrm{Mg} \mathrm{ha}^{-1}$ de esterco. No primeiro crescimento desse cultivar, a produção de massa seca foi composta praticamente de folhas, devido ao estádio inicial de desenvolvimento das plantas, o que pode justificar maior relação folha/colmo nesse período.

No $2^{\circ}$ corte, apesar do comportamento quadrático, observa-se que nas maiores doses de esterco, a relação folha/colmo diminuiu. O decréscimo da relação folha/colmo, de acordo com Rodrigues et al. (2014), compromete a eficiência do pastejo. Rodrigues et al. (2008) também verificaram diminuição na relação folha/colmo com o aumento das doses de $\mathrm{N}$ e atribuíram este resultado ao maior crescimento das plantas e ao processo de alongamento dos colmos.

Ainda segundo os autores, os efeitos negativos na relação folha/colmo em função do aumento das doses de $\mathrm{N}$ podem ser compensados parcialmente ou totalmente pelo benefício do aumento em produção de fitomassa. A adubação inorgânica proporcionou resultados semelhantes às duas maiores doses de esterco aplicadas.

De acordo com Zanine e Ferreira (2015) a utilização de esterco como adubo orgânico é uma alternativa viável, eficiente e de baixo impacto ambiental porque fornece diversos nutrientes essenciais à produção de forragem, em especial para o fornecimento de nitrogênio, todavia é importante maiores estudos a fim de determinar doses necessárias à nutrição da espécie forrageira.

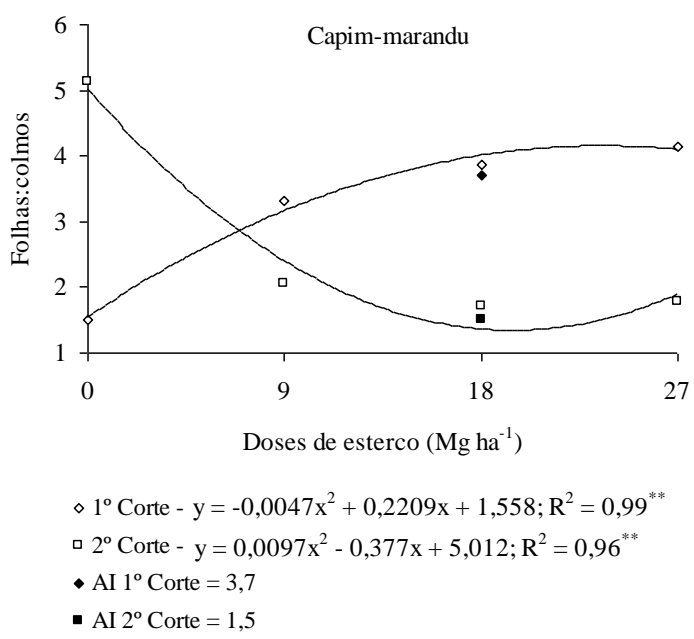

Figura 5. Relação folha/colmo do capim-marandu em função da aplicação de doses de esterco bovino e da adubação inorgânica (AI). São Luís de Montes Belos/GO.

\section{Conclusões}

A adubação orgânica, na forma de esterco bovino, influenciou de forma positiva o desenvolvimento e produtividade das forrageiras.

A máxima produtividade do capim-marandu foi obtida com a dose média $24,3 \mathrm{Mg} \mathrm{ha}^{-1}$ de esterco bovino e o capim-mombaça respondeu até a máxima dose aplicada (36 $\left.\mathrm{Mg} \mathrm{ha}^{-1}\right)$.

A adubação inorgânica proporcionou resultados semelhantes às duas maiores doses de esterco aplicadas (18 e $27 \mathrm{Mg} \mathrm{ha}^{-1}$ para o capim-marandu e 18 e $36 \mathrm{Mg}$ $\mathrm{ha}^{-1}$ para o capim-mombaça).

\section{Referências Bibliográficas}

ALEXANDRINO, E.; VAZ, R. G. M. V.; SANTOS, A. C. Características da Brachiaria brizantha cv. marandu durante o seu estabelecimento submetida a diferentes doses de nitrogênio. Bioscience Journal, Uberlândia-MG, v. 26, n. 06, p. 886-893, 2010.

ALEXANDRINO, E.; NASCIMENTO JÚNIOR, D.; REGAZZI, A. J.; MOSQUIM, P. R.; ROCHA, F. C.; SOUZA, D. P. Características morfogênicas e estruturais de Brachiaria brizantha cv. Marandu submetida a diferentes doses de nitrogênio e frequências de cortes. Acta Scientitarum Agronomy, Maringá-PR, v. 27, n. 01, p. 17 - 24, 2005.

ALVIM, M. J.; BOTREL, M. A.; XAVIER, D. F. As principais espécies de Brachiaria utilizadas no País. Juiz de Fora-MG: Embrapa Gado de Leite, 2002, 4 p. (Circular Técnica 22).

ARAUJO, A. S; SILVA, J. E. C.; SANTOS, A. C.; SILVA NETO, S. P.; DIM, V. P.; ALEXANDRINO, E. Substituição de nitrogênio por esterco bovino na produtividade de forragem e qualidade do solo. Revista Brasileira de Saúde e Produção Animal, Salvador-BA, v. 12, n. 4, p. 852-866, 2011. 
ARAUJO, F.F. de; TIRITAN, C.S.; OLIVEIRA, T.R.de. Compostos orgânicos semicurados na adubação de pastagem degradada de Brachiaria decumbens. Revista Ciência Agronômica, Fortaleza-CE, v. 40, n. 1, p. 1-6, 2009.

EDVAN, R. L.; SANTOS, E. M.; VASCONCELOS, W. A.; SOUTO FILHO, L. T.; BORBUREMA, J. B.; MEDEIRO, G. R.; ANDRADE, A. P. Utilização de adubação orgânica em pastagem de capim-buffel (Cenchurus ciliares cv. Molopo). Archivos de Zootecnia, Córdoba, Andalucía, v.59, p.499-508, 2010.

CAMINHA, F. O.; SILVA, S. C.; PAIVA, A. J.; PEREIRA, L. E. T.; MESQUITA, P.; GUARDA, V. D. Estabilidade da população de perfilhos de capim - marandu sob lotação contínua e adubação nitrogenada. Pesquisa Agropecuária Brasileira, Brasília-DF, v. 45, n. 02, p. 213-220, 2010.

EMBRAPA. EMPRESA BRASILEIRA DE PESQUISA AGROPECUÁRIA. Sistema brasileiro de classificação de solos. $3^{\text {a }}$ ed. Brasília-DF: EMBRAPA, 2013. 353p.

FERREIRA, D. F. Sisvar versão 4.2. DEX/UFLA, 2015.

HOFFMANN, A.; MORAES, E. H. B. K.; MOUSQUER, C. J.; SIMONI, T. A.; JUNIOR GOMES, F.; FERREIRA, V. B.; SILVA, H. M. Produção de bovinos de corte no sistema de pasto-suplemento no período seco. Pesquisas Agrárias e Ambientais, Sinop-MT, v. 02, n. 02, p. 119-130, 2014.

MARTINS, R. L.; ROSSI JUNIOR, P.; FERNANDES, A. C.; GRISE, M. M.; MURARO, G. B. Produção de Forragem em pastagens de Brachiaria brizantha cv. Marandu e Panicum maximum cv. Mombaça, em resposta a diferentes doses de nutrientes, em Umuarama - PR. Revista Acadêmica: Ciência Animal, Curitiba-PR, v. 4, n. 3, p. 59-64, 2006.

MAZZA, L. M.; PÔGGERE, G. C.; FERRARO, F. P.; RIBEIRO, C. B.; CHEROBIM, V. F.; MOTTA, A. C. V.; MORAES, A. Adubação nitrogenada na produtividade e composição química do capim mombaça no primeiro planalto paranaense. Scientia Agrária, Curitiba-PR, v. 10, n. 4, p. $257-$ 265, 2009.

MELLO, S. Q. S.; FRANÇA, A. F. S.; LANNA, A. C.; BERGAMASCHINE, A. F.; KLIMANN, H. J.; RIOS, L. C.; SOARES, T. V. Adubação nitrogenada em capim Mombaça produção, eficiência de conversão e recuperação aparente do nitrogênio. Ciência Animal Brasileira, Goiânia-GO, v. 09, n. 04, p. 935-947, 2009.

MÜLLER, M. S.; FANCELLI, A. L.; DOURADO-NETO, D.; GARCÍA, A. G. Y; OVEJERO, R. F. L. Produtividade do Panicum maximum cv. Mombaça irrigado, sob pastejo rotacionado. Scientia Agrícola, São Paulo-SP, v. 59, n. 03, p. 427-433, 2002.
NERES, M. A.; MESQUITA, E. E.; OLIVEIRA, P. S. R.; OLIVEIRA, E. Características estruturais de cultivares de Panicum maximum Jacq. em função da adubação nitrogenada. Scientia Agraria Paranaensis, Marechal Cândido RondonPR, v. 7, s/n, p. 25-33, 2008.

RODRIGUES, R. C.; AMORIM, S. E. P.; MELLO, M. A. A.; SANTOS, C. C.; SANCHÊS, S. S. C.; GALVÃO, C. M. L. Características morfogênicas e estruturais do capim-Xaraés submetido a intensidades de desfolhas. Revista Brasileira de Saúde Produção Animal, Salvador-BA, v.15, n.2, p.430-439, 2014.

RODRIGUES, R.C.; MOURÃO, G.B.; BRENNECKE, K.; LUZ, P.H.C.; HERLING, V.R. Produção de massa seca, relação folha/colmo e alguns índices de crescimento do Brachiaria brizantha cv. Xaraés cultivado com a combinação de nitrogênio e potássio. Revista Brasileira de Zootecnia, Viçosa-MG, v. 37, n. 3, p. 394-400, 2008.

SEAB. SECRETARIA DE ESTADO DA AGRICULTURA E DO ABASTECIMENTO. Análise da conjuntura agropecuária: leite - ano 2014. Brasil: SEAB, 2014. 21 p.

SILVA, D. R. G.; COSTA, K. A. P.; FAQUIN, V.; OLIVEIRA, I. P.; BERNARDES, T. F. Doses e fontes de nitrogênio na recuperação das características estruturais e produtivas do capim-marandu. Revista Ciência Agronômica, Fortaleza-CE, v.44, n.1, p.184-191, 2003

SILVA, T. O.; SANTOS, A. R.; SANTOS, J. H.; SILVA, J. O. Produção do capim Marandu submetido a doses de nitrogênio em um Latossolo amarelo. Agropecuária Técnica, João Pessoa-PB, v. 26, n. 1, p. 29-35, 2005.

SILVA, A. A.; SIMIONI, G. F.; LUCENA, A. Efeito da adubação orgânica no crescimento do capim Brachiaria brizantha cv. marandu em parecis/rondônia. Enciclopédia Biosfera, Centro Científico Conhecer. Goiânia-GO, v. 9, n. 16, p. 923 - 932, 2012.

SOUZA, R.F.; FAQUIN, V.; SOBRINHO, R.R.L.; OLIVEIRA, E.A.B. Influência de esterco bovino e calcário sobre o efeito residual da adubação fosfatada para a Brachiaria brizantha cultivada após o feijoeiro. Revista Brasileira de Ciência do Solo, Viçosa-MG, v. 34, n. 01, p.143-150, 2010.

ZANINE, A. M.; FERREIRA, D. J. Animal Manure as a Nitrogen Source to Grass. American Journal of Plant Sciences. Delaware: USA, v. 06, n. 07, p. 899 - 910, 2015. 